\title{
Comparative Study Between Lumbar Epidural Versus Transversus Abdominis Plane Block For Postoperative Analgesia After Lower Abdominal Surgeries
}

\author{
Ismail A. Shabayek, Ahmed M. El-Garhy, Walid N. Soliman \\ Department of Anesthesia and Intensive care \\ Corresponding author: Walid N. Soliman; Mobile: 01063268156; Email: walidnashaat744@gmail.com
}

\begin{abstract}
Background: Postoperative pain is a potent cause of adverse effects in many organ systems thus anterior abdominal wall analgesia after abdominal surgery may assist in improving postoperative outcome. The analgesic regimen needs to meet the goals of providing safe, effective analgesia, with minimal side effects for the patient, together with inhibition of trauma -induced nociceptive impulses. Aim of the work: to compare the analgesic efficacy of transversus abdominis plane block with lumber epidural analgesia for postoperative pain relief following lower abdominal surgeries. Patients and methods: The present study was carried out at Al-Azhar University Hospitals (Al-Hussien and SayedGalal) after institutional ethics and informed consent. 90 adult patients were randomized into three groups (30 patients in each group): Lumbar epidural group, Transversus abdominis plane block group and A Control group. Results: As regards postoperative hemodynamic data, higher readings appeared within the control group, while the epidural group and TAP group showed lower readings with no statically difference among the three groups, except at the first 10 minutes and 20 minutes time periods after starting the epidural analgesia and application of the TAP block. As regard pain scoring using the visual analog scale (VAS), the results showed no statically difference among the three groups with $(\mathrm{P}>0.05)$, except at the first 10 minutes and 20 minutes time periods after starting the epidural analgesia and application of the TAP block, highest readings were realized among the control group at these two time periods in comparison with the other two groups with $\mathrm{P}<0.05$. Patients of the control group were the first to ask for rescue analgesia. Rate of administration of the rescue analgesia was seen to be more frequent among patients of the control group rather than the other two groups with $(\mathrm{P}<0.05)$.Postoperative complications as, (nausea and vomiting) which occurred due to systemic use of opioids were mostly seen among the control group rather than the other two groups with $(\mathrm{P}<0.05)$ Conclusion: Use of the TAP block proved to be a simple and safe procedure in providing effective reliable analgesia, together with reduction of postoperative pain scores, both at rest and knee flexion, and postoperative opioid requirements thus avoided any of the systemic side effect of opioid such as PONA as seen among the control group. Recommendations: The blind application of this technique might have been associated with major complication although we didn't experienced any, yet performing this block under ultrasound guidance facilitates identification of the needle tip in the TAP, and may result in reduced risk, particularly in obese patient with BMI $>30 \mathrm{~kg} / \mathrm{m}^{2}$.
\end{abstract}

Keywords: lumbar epidural, Transversus abdominis plane block, postoperative analgesia, analgesia, lower abdominal surgery

\section{INTRODUCTION}

Pain continues to be a significant problem for many patients after surgery. In addition to improving patient satisfaction and decreasing pain scores, enhanced perioperative pain control can improve clinical outcomes ${ }^{(\mathbf{1})}$.

Abdominal field blocks have been used in anesthesia for surgery involving the anterior abdominal wall for several decades. The Transversus Abdominis Plane (TAP) block is a technique involving multiple injections of local anesthetic in the abdominal wall was used in the $1980 \mathrm{~s}^{(2)}$.

This technique improved with a blind landmark technique, via the 'lumbar triangle of Petit' (3).

The clinical efficacy of the landmark technique and, more recently, ultrasound-guided procedures has been investigated in severalcenters around the world ${ }^{(4)}$.
The TAP block provides analgesia to the parietal peritoneum as well as the skin and muscles of the anterior abdominal wall. It has a high margin of safety and is technically simple to perform, especially under ultrasound guidance ${ }^{(5)}$.

Lumbar Epidural Analgesia (LEA) remains a main tool for anesthesiologists to use in acute pain management. LEA is particularly useful for reducing pain after abdominal surgeries and likely permits major surgical procedures to be performed on patients with moderate to severe comorbid diseases, who several years ago may have been determined to be too high a risk for surgery ${ }^{(1)}$.

There is clear evidence that epidural analgesia provides better postoperative analgesia compared to parenteral opioids ${ }^{(6)}$.

It also enhances functional exercise capacity, health-related quality of life, and reduces hospital stay after abdominal surgery ${ }^{(7)}$. 


\section{AIM OF THE WORK}

The study aimed at comparing the analgesic efficacy of transversus abdominis plane block with lumber epidural analgesia for postoperative pain relief following lower abdominal surgeries.

\section{PATIENTS AND METHODS}

The present study was carried out at AlAzhar University Hospitals (Al-Hussien and Sayed Galal) after institutional ethics and informed consent. 90 adult patients were randomized into three groups (30 patients in each group): Group $\mathbf{E}$ (30 patients): Lumbar Epidural group. Members of this group received general anesthesia after insertion of lumber epidural catheter. Epidural injection was utilized only for postoperative analgesia. Group T (30 patients): Transversus Abdominis Plane block Group.Members of this group received general anesthesia and at the end of the surgical procedure and before emergence, TAP block was performed for postoperative analgesia. Group C(30 Patients): Control group. Members of this group received general anesthesia only.

Inclusion criteria: Age: 19 to 60 years old. Both genders are eligible. ASA class I or II patients. Patients undergoing lower abdominal surgeries.

Exclusion criteria: Patients with hypersensitivity to local anesthetics. Patients with contraindications to neuraxial procedures. Patients with diabetes mellitus.

Allpatients were informed about the study design and objectives as well as tools and techniques. Every patient took written consent before inclusion in the study.

During the pre-anesthetic check up visit, all patients were explained and familiarized about the study including the use of visual analogue scale for pain assessment ( 0 as "no pain" to 10 as "worst intolerable pain").

\section{Anesthetic technique:}

Preoperative assessment: All patients further evaluated by medical history, physical examination and clinical laboratory test. All patients were premeditated after insertion of the intravenous cannula with Midazolam $(0.05 \mathrm{mg} / \mathrm{kg}$ IV)half an hour before induction.

Intraoperative management: In the operating room, standard monitoring was applied,
Baselinevital signsweretaken before anesthesia induction, and general anesthesia was induced after preoxygenation for four minutes by Fentanyl (2 $\mu \mathrm{g} / \mathrm{kg} \mathrm{IV})$, Propofol (2 mg/kg IV) and Atracurium $(0.5 \mathrm{mg} / \mathrm{kg}$ IV $)$ to facilitate tracheal intubation. After induction, the appropriate size endotracheal tube was inserted. Anesthesia maintained by volume controlled ventilation mode (maintain $\mathrm{O} 2$ saturation $>98 \%$ and ETCO2 around 35-38 $\mathrm{mmHg}$ ), Isoflurane (1-1.5\%) and Atracurium (0.1 $\mathrm{mg} / \mathrm{kgIV}$ ) every 20 minutes guided by nerve stimulator. At the end of the operation, Isoflurane was discontinued, and muscle relaxant was reversed by a mixture of Neostigmine $(0.04 \mathrm{mg} / \mathrm{kg})$ and Atropine $(0.01 \mathrm{mg} / \mathrm{kg})$ then the patients were extubated after fulfilling extubationcriteria.

\section{Analgesic Regimens:}

Group-E: Before induction of anesthesia, midline approach Lumber epidural was used. Patients sit with their elbows resting on their thighs. Arching back (like amad cat) maximizes target interspace. A sterile field was established with betadine or similar solution. A line drown between superior aspects of iliac crest (Tuffier"s line) usually crosses L4-L5 interspace. Infiltration of the skin and subcutaneous tissues with local anesthetic at the level of L4-L5 interspace using a small (25-gauge) needle. Epidural space was identified by loss of resistance technique with air filled syringe, using the Bromage grip. Tuohy needle $(18 \mathrm{G})$ was introduced midline at L4 - L5 interspace with intermittent compression of the syringe plunger attached to the Tuohy needle. Epidural space was identified at $3-5 \mathrm{~cm}$ from skin level. An epidural catheter was threaded into the epidural space via the epidural needle and catheter was fixed so that $5 \mathrm{~cm}$ of the catheter was in the epidural space. The catheter was secured using a sterile locking device and adherent dressings. At the end of surgery patients of this group receivedan initial dose of $60 \mathrm{mg}$ xylocaine as a test dose. Loading dose was given (total volume $1 \mathrm{ml}$ every segment with Bupivacaine 0.125\%). Maintenance dose (1/2 loading dose) was given every 2 hours.

Group-T: The TAP block was performed at the end of the surgery in the supine position before emergence, asterile field was established with betadine or similar solution. TAP block was performed by double pop technique. The iliac crest was first palpated from anterior to posterior until the latissimusdorsi muscle could be felt. The 
triangle of Petit was then located just anterior to the latissimusdorsi muscle. The depth of TAP at the position of the lumbar triangle of Petit was between 0.5 and $4.0 \mathrm{~cm}$, dependent on adipose tissue. Using an atraumatic echogenic $20 \mathrm{G}$ needle with injection port attached to a flexible tubing system which will be connected toa syringe filled with the local anesthetic, the skin is then pierced just cephalad to the iliac crest over the triangle of Petit. This resistance indicates that the needle tip is at the external oblique muscle. Gentle advancement of the needle resulted in a "pop" sensation as the needle entered the plane between the external and internal oblique fascial layers. Further gentle advancement of the needle resulted in a second pop, which indicates entry into the Transversus abdominisfascial plane. The needle is then advanced perpendicularly to the skin slightly behind the midaxillary line, in a coronal plane, until resistance was encountered. After careful aspiration to exclude vascular puncture, $15 \mathrm{ml}$ of $0.125 \%$ of isobaric bupivacaine solution with a maximum dose of $3 \mathrm{mg} / \mathrm{kg}$, was injected through the needle. The same procedure was done on the contralateral side.

Group C: Patients of this group received general anesthesia as mentioned above, with no further administration of narcotics.

\section{Postoperative management:}

All patients of the three groups were monitored by: Mean arterial pressure (MAP), heart rate (HR) and respiratory rate (RR) at 0,10,20,40 and 60 minutes postoperatively, then at 2,4,6 and 12 hours during the postoperative period. Visual Analogue Scale (VAS)was used to assess postoperative pain at $0,10,20,40$ and 60 minutes postoperatively, then at 2,4,6 and 12 hours during the postoperative period. For all patients of the three groups, rescue pain analgesia was given postoperatively for visual analogue scale (VAS) $\geq 4$ by Pethidine $(1 \mathrm{mg} / \mathrm{kg} \mathrm{IV}$ ). VAS was reassessed 10 minutes later to any rescue analgesic injection. Time of the first request of analgesia and average total consumption of analgesics. Postoperative nausea and vomiting and The average total consumption of antiemetic (metoclopramide). Hospital length of stay

\section{Statistical analysis:}

Recorded data were analyzed using the statistical package for social sciences, version 20.0 (SPSS Inc., Chicago, Illinois, USA). Quantitative data were expressed as mean \pm standard deviation (SD). Qualitative data were expressed as frequency and percentage.

The following tests were done: A one-way analysis of variance (ANOVA) when comparing between more than two means. Kruskall Wallis test: for multiple-group comparisons in non-parametric data. Chi-square $\left(\mathrm{x}^{2}\right)$ test of significance was used in order to compare proportions between two qualitative parameters. The confidence interval was set to $95 \%$ and the margin of error accepted was set to $5 \%$. So, the p-value was considered significant as the following: Probability (P-value). P-value $<0.05$ was considered significant. P-value $<0.001$ was considered as highly significant. P-value $>0.05$ was considered insignificant.

\section{RESULTS}

After approval of the departmental ethical committee, this randomized study was conducted at Al-Azhar University Hospitals (Al-Hussien and SayedGalal) after institutional ethics and informed consent. 90 adult patients were randomized into three groups (30 patients in each group):

Group E (30 patients): Lumbar Epidural group. Members of this group received general anesthesia after insertion of lumber epidural catheter. Epidural injection was utilized only for postoperative analgesia.

Group $\mathbf{T}$ (30 patients): Transversus Abdominis Plane block group. Members of this group received general anesthesia and at the end of the surgical procedure and before emergence, TAP block was performed for postoperative analgesia using double pop technique.

Group C (30 Patients): Control group. Members of this group received general anesthesia only.

\section{Postoperative Hemodynamic Status Representation:}

As regards postoperative hemodynamic data, are being represented in this study as mean arterial blood pressure, mean heart rate and mean respiratory rate (Tables 1, 2and 3), which show no statically difference among the three groups at any time during assessment, except at the first 10 minutes and 20 minutes time periods after starting the epidural analgesia and application of the TAP block.

Higher readings of mean arterial blood pressure appeared within the control group, while 
the epidural group showed the lowest readings especially after the first 10 minutes postoperatively.

Table (1): Postoperative mean arterial blood pressure.

\begin{tabular}{|l|c|c|c|c|c|}
\hline $\begin{array}{c}\text { Time of } \\
\text { assessment }\end{array}$ & $\begin{array}{c}\text { Epidural } \\
(\mathbf{N}=\mathbf{3 0})\end{array}$ & $\begin{array}{c}\text { TAP } \\
(\mathbf{N}=\mathbf{3 0})\end{array}$ & $\begin{array}{c}\text { Control } \\
(\mathbf{N}=\mathbf{3 0})\end{array}$ & ANOVA & $\begin{array}{c}\text { p- } \\
\text { value }\end{array}$ \\
\hline $\begin{array}{l}\text { 0 min. (At } \\
\text { PACU) }\end{array}$ & $90.90 \pm 0.76$ & $91.91 \pm 0.25$ & $91.91 \pm 0.51$ & 1.195 & $0.287 \mathrm{NS}$ \\
\hline At 10 min. & $83.81 \pm 3.03^{*} \dagger$ & $88.88 \pm 0.51^{*}$ & $91.91 \pm 2.53$ & 4.314 & $0.026 \mathrm{~S}$ \\
\hline At 20 min. & $87.37 \pm 1.52^{*}$ & $87.87 \pm 1.52^{*}$ & $89.89 \pm 0.76$ & 5.392 & $0.039 \mathrm{~S}$ \\
\hline At 40 min. & $87.87 \pm 2.02$ & $87.87 \pm 1.52$ & $88.88 \pm 0.76$ & 0.956 & $0.229 \mathrm{NS}$ \\
\hline At 60 min. & $87.87 \pm 1.52$ & $87.87 \pm 1.52$ & $88.88 \pm 1.52$ & 1.275 & $0.306 \mathrm{NS}$ \\
\hline At 2 hrs. & $86.86 \pm 2.02$ & $86.86 \pm 1.77$ & $87.87 \pm 1.11$ & 0.757 & $0.182 \mathrm{NS}$ \\
\hline At 4 hrs. & $88.88 \pm 0.51$ & $88.88 \pm 0.25$ & $88.88 \pm 0.10$ & 1.135 & $0.272 \mathrm{NS}$ \\
\hline At 6 hrs. & $87.87 \pm 0.75$ & $87.87 \pm 0.51$ & $87.87 \pm 0.25$ & 0.908 & $0.218 \mathrm{NS}$ \\
\hline At 12 hrs. & $88.88 \pm 0.51$ & $88.88 \pm 0.25$ & $88.88 \pm 0.10$ & 1.211 & $0.291 \mathrm{NS}$ \\
\hline
\end{tabular}

S: Significant; NS: Non-Significant

Data are demonstrated as mean \pm SD. TAP; Transversus abdominis plane block, $*=$ in comparison to the control group, $\dagger=$ in comparison to the TAP group, $\mathrm{P}<0.05=$ statically significant, $\mathrm{P}>0.05=$ statically not significant.

Table (2): Postoperative mean value of heart rate.

\begin{tabular}{|l|c|c|c|c|c|}
\hline $\begin{array}{c}\text { Time of } \\
\text { assessment }\end{array}$ & $\begin{array}{c}\text { Epidural } \\
(\mathbf{N}=\mathbf{3 0})\end{array}$ & $\begin{array}{c}\text { TAP } \\
(\mathbf{N}=\mathbf{3 0})\end{array}$ & $\begin{array}{c}\text { Control } \\
(\mathbf{N}=\mathbf{3 0})\end{array}$ & ANOVA & p-value \\
\hline 0 min. (At PACU) & $79.39 \pm 4.44$ & $80.50 \pm 3.33$ & $81.31 \pm 2.53$ & 0.863 & $0.207 \mathrm{NS}$ \\
\hline At 10 min. & $73.33 \pm 3.55^{*}$ & $74.36 \pm 2.53^{*}$ & $89.39 \pm 2.53$ & 5.840 & $0.035 \mathrm{~S}$ \\
\hline At 20 min. & $73.33 \pm 3.56^{*}$ & $74.34 \pm 2.54^{*}$ & $88.17 \pm 2.53$ & 3.893 & $0.028 \mathrm{~S}$ \\
\hline At 40 min. & $78.83 \pm 4.55$ & $80.09 \pm 3.28$ & $80.85 \pm 2.53$ & 1.150 & $0.276 \mathrm{NS}$ \\
\hline At 60 min. & $78.83 \pm 4.55$ & $80.09 \pm 3.28$ & $80.85 \pm 2.53$ & 0.683 & $0.164 \mathrm{NS}$ \\
\hline At 2 hrs. & $78.83 \pm 4.55$ & $80.09 \pm 3.28$ & $80.85 \pm 2.53$ & 1.025 & $0.246 \mathrm{NS}$ \\
\hline At 4 hrs. & $77.77 \pm 1.52$ & $76.76 \pm 1.52$ & $76.76 \pm 0.76$ & 0.820 & $0.197 \mathrm{NS}$ \\
\hline At 6 hrs. & $77.77 \pm 0.51$ & $76.76 \pm 1.31$ & $76.76 \pm 1.41$ & 1.093 & $0.262 \mathrm{NS}$ \\
\hline At 12 hrs. & $77.77 \pm 0.51$ & $76.76 \pm 1.31$ & $76.76 \pm 1.41$ & 0.649 & $0.156 \mathrm{NS}$ \\
\hline
\end{tabular}

S: Significant; NS: Non-Significant

Table (3): Postoperative respiratory rate.

\begin{tabular}{|l|c|c|c|c|c|}
\hline & $\begin{array}{c}\text { Epidural } \\
(\mathbf{N}=\mathbf{3 0})\end{array}$ & $\begin{array}{c}\text { TAP } \\
(\mathbf{N}=\mathbf{3 0})\end{array}$ & $\begin{array}{c}\text { Control } \\
(\mathbf{N}=\mathbf{3 0})\end{array}$ & ANOVA & p-value \\
\hline $\begin{array}{l}\text { 0 min. (At } \\
\text { PACU) }\end{array}$ & $18.4 \pm 1.1$ & $18.3 \pm 1.8$ & $18.9 \pm 0.2$ & 0.505 & 0.475 \\
\hline At 10 min. & $17.3 \pm 1.5^{*}$ & $17.4 \pm 1.1^{*}$ & $19.3 \pm 0.1$ & 7.287 & $<0.001^{* *}$ \\
\hline At 20 min. & $17.3 \pm 1.6^{*}$ & $17.5 \pm 1.2^{*}$ & $18.5 \pm 0.1$ & 4.100 & $<0.001^{* * *}$ \\
\hline At 40 min. & $17.4 \pm 1.1$ & $17.4 \pm 1.1$ & $17.8 \pm 0.2$ & 0.743 & 0.699 \\
\hline At 60 min. & $17.6 \pm 1.4$ & $17.3 \pm 0.9$ & 18.000 .1 & 0.108 & 0.101 \\
\hline At 2 hrs. & $17.4 \pm 1.7$ & $17 . \pm \pm 0.7$ & $17.9 \pm 0.1$ & 0.244 & 0.230 \\
\hline At hrs. & $17.2 \pm 1.7$ & $17.6 \pm 0.7$ & $17.7 \pm 0.1$ & 0.261 & 0.245 \\
\hline At 6 hrs. & $17.4 \pm 1.0$ & $17.8 \pm 0.6$ & $17.7 \pm 0.1$ & 0.474 & 0.446 \\
\hline At 12 hrs. & $17.6 \pm 1.3$ & $17.1 \pm 0.9$ & $17.7 \pm 0.2$ & 0.257 & 0.241 \\
\hline
\end{tabular}

\section{Postoperative Pain Scoring:}

As regard pain scoring in this study, it is being represented using the visual analog scale (VAS) along the whole periods of assessment at both; the rest and the dynamic (knee flexion) states respectively as seen in (Tables 4, and 5).

More interestingly, our data showed no statically difference among the three groups with ( $P>0.05)$, except at the first 10 minutes and 20 minutes time periods after starting the epidural analgesia and application of the TAP block.
Highest readings were realized among the control group at these two time periods in comparison with the other two groups with $\mathrm{P}<0.05$.

Table (4): Visual analog scale at rest state.

\begin{tabular}{|l|c|c|c|c|c|}
\hline $\begin{array}{c}\text { Time of } \\
\text { assessment }\end{array}$ & $\begin{array}{c}\text { Epidural } \\
(\mathbf{N = 3 0})\end{array}$ & $\begin{array}{c}\text { TAP } \\
(\mathbf{N = 3 0})\end{array}$ & $\begin{array}{c}\text { Control } \\
(\mathbf{N = 3 0})\end{array}$ & ANOVA & p-value \\
\hline $\begin{array}{l}0 \text { min. (At } \\
\text { PACU) }\end{array}$ & $3.03 \pm 1.52$ & $3.54 \pm 1.01$ & $4.04 \pm 0.51$ & 1.038 & $0.249 \mathrm{NS}$ \\
\hline At 10 min. & $2.02 \pm 1.52^{*}$ & $3.03 \pm 0.51^{*}$ & $6.06 \pm 2.53$ & 4.623 & $0.033 \mathrm{~S}$ \\
\hline At $20 \mathrm{~min}$. & $2.02 \pm 1.52^{*}$ & $3.03 \pm 0.51^{*}$ & $5.15 \pm 0.51$ & 3.699 & $0.027 \mathrm{~S}$ \\
\hline At $40 \mathrm{~min}$. & $2.15 \pm 1.47$ & $2.94 \pm 0.49$ & $2.76 \pm 0.49$ & 0.956 & $0.230 \mathrm{NS}$ \\
\hline At 60 min. & $2.22 \pm 1.52$ & $3.03 \pm 0.51$ & $3.03 \pm 0.51$ & 0.986 & $0.237 \mathrm{NS}$ \\
\hline At 2 hrs. & $2.55 \pm 1.75$ & $3.48 \pm 0.59$ & $3.18 \pm 0.59$ & 1.134 & $0.273 \mathrm{NS}$ \\
\hline At 4 hrs. & $2.68 \pm 0.25$ & $2.07 \pm 0.86$ & $2.17 \pm 0.76$ & 0.586 & $0.141 \mathrm{NS}$ \\
\hline At 6 hrs. & $1.97 \pm 0.25$ & $1.41 \pm 0.76$ & $2.07 \pm 0.15$ & 0.878 & $0.211 \mathrm{NS}$ \\
\hline At 12 hrs. & $1.72 \pm 0.45$ & $1.62 \pm 0.56$ & $2.02 \pm 0.15$ & 0.703 & $0.169 \mathrm{NS}$ \\
\hline
\end{tabular}

S: Significant; NS: Non-Significant

Table (5): Visual analogue scale at Dynamic State (knee flexion).

\begin{tabular}{|c|c|c|c|c|c|}
\hline $\begin{array}{c}\text { Time of } \\
\text { assessment }\end{array}$ & $\begin{array}{c}\text { Epidural } \\
(\mathbf{N}=30)\end{array}$ & $\begin{array}{c}\text { TAP } \\
(\mathbf{N}=\mathbf{3 0})\end{array}$ & $\begin{array}{l}\begin{array}{l}\text { Control } \\
(\mathbf{N}=30)\end{array} \\
\end{array}$ & ANOVA & p-value \\
\hline $\begin{array}{l}0 \text { min. (At } \\
\text { PACU) }\end{array}$ & $3.03 \pm 1.52$ & $3.03 \pm 1.52$ & $4.04 \pm 0.51$ & 0.937 & $0.225 \mathrm{NS}$ \\
\hline At $10 \mathrm{~min}$. & $3.03 \pm 1.52 *$ & $3.54 \pm 1.52 *$ & $7.07 \pm 1.52$ & 2.643 & $0.019 \mathrm{~S}$ \\
\hline At $20 \mathrm{~min}$. & $2.53 \pm 1.52 *$ & $3.54 \pm 0.51 *$ & $6.06 \pm 1.52$ & 3.964 & $0.029 \mathrm{~S}$ \\
\hline At $40 \mathrm{~min}$. & $2.06 \pm 1.47$ & $2.37 \pm 1.06$ & $2.76 \pm 0.49$ & 0.539 & $0.130 \mathrm{NS}$ \\
\hline At $60 \mathrm{~min}$. & $2.12 \pm 1.52$ & $2.44 \pm 1.09$ & $3.03 \pm 0.51$ & 0.556 & $0.134 \mathrm{NS}$ \\
\hline At 2 hrs. & $2.44 \pm 1.75$ & $2.81 \pm 1.25$ & $3.18 \pm 0.59$ & 0.639 & $0.154 \mathrm{NS}$ \\
\hline At $4 \mathrm{hrs}$. & $2.44 \pm 1.09$ & $2.02 \pm 1.52$ & $2.78 \pm 0.76$ & 0.835 & $0.200 \mathrm{NS}$ \\
\hline At 6 hrs. & $1.21 \pm 1.62$ & $2.32 \pm 0.51$ & $2.22 \pm 0.61$ & 0.668 & $0.160 \mathrm{NS}$ \\
\hline At 12 hrs. & $1.01 \pm 1.82$ & $1.31 \pm 1.52$ & $2.02 \pm 0.81$ & 0.890 & $0.214 \mathrm{NS}$ \\
\hline
\end{tabular}

S: Significant; NS: Non-Significant

\section{Rescue Analgesia Analysis:}

Rescue pain analgesia was given postoperatively for visual analogue scale (VAS) $\geq$ 4 by IV infusion of $30 \mathrm{mg}$ Ketorolac and/or pethidine $1 \mathrm{mg} / \mathrm{kg}$ IV to be reassessed every 4 to 6 hours for the degree of pain. Time to the first rescue analgesia together with number of administration through the 12 hours, as well as postoperative complications were recorded.

Patients of the control group were the first to ask for rescue analgesia while calling for rescue analgesia was delayed in both the epidural and the TAP block with $(\mathrm{P}<0.05)$ as in (Table 6$)$.

Rate of administration of the rescue analgesia was seen to be more frequent among patients of the control group rather than the other two groups with $(\mathrm{P}<0.05)$ as in (Table 7$)$.

Postoperative complications as, (nausea and vomiting) which occurred due to systemic use of opioids were mostly seen among the control group rather than the other two groups with $(\mathrm{P}<0.05)$ as in (Table 8). 
Table (6): Time of the first dose of the rescue Analgesia.

\begin{tabular}{|l|c|c|c|c|c|}
\hline & $\begin{array}{c}\text { Epidural } \\
(\mathbf{N}=30)\end{array}$ & $\begin{array}{c}\text { TAP } \\
(\mathbf{N}=\mathbf{3 0})\end{array}$ & $\begin{array}{c}\text { Control } \\
(\mathbf{N}=30)\end{array}$ & ANOVA & p-value \\
\hline $\begin{array}{l}\text { Time to the } \\
\text { first dose } \\
(\mathrm{min})\end{array}$ & $121.50 \pm 20.63^{*}$ & $172.00 \pm 15.35^{*}$ & $10.30 \pm 8.08$ & 7.634 & $\begin{array}{c}<0.001 \\
\mathrm{HS}\end{array}$ \\
\hline
\end{tabular}

HS: Highly Significant

Table (7): Number of doses of Rescue Analgesia (Pethidine/ketorolac).

\begin{tabular}{|l|c|c|c|c|c|}
\hline $\begin{array}{c}\text { Rescue } \\
\text { analgesia }\end{array}$ & $\begin{array}{c}\text { Epidural } \\
(\mathbf{N}=\mathbf{3 0})\end{array}$ & $\begin{array}{c}\text { TAP } \\
(\mathbf{N}=\mathbf{3 0})\end{array}$ & $\begin{array}{c}\text { Control } \\
(\mathbf{N}=\mathbf{3 0})\end{array}$ & ANOVA & p-value \\
\hline Pethidine & $2.32 \pm 1.04^{*}$ & $1.26 \pm 0.84^{*} \dagger$ & $3.94 \pm 0.45$ & 5.920 & $0.030 \mathrm{~S}$ \\
\hline Ketorolac & $1.65 \pm 0.55^{*}$ & $1.47 \pm 0.66^{*}$ & $3.54 \pm 1.47$ & 3.515 & $0.018 \mathrm{~S}$ \\
\hline Both & $3.13 \pm 0.40^{*}$ & $1.21 \pm 0.20^{*} \dagger$ & $4.34 \pm 0.20$ & 5.272 & $0.027 \mathrm{~S}$ \\
\hline
\end{tabular}

S: Significant;

Data are represented as mean $\pm \mathrm{SD}$. Rescue pain analgesia for VAS $\geq 5$ by Ketorolac $(30 \mathrm{mg}$ ) and/or Pethidine $(1 \mathrm{mg} / \mathrm{kg})$, IV. TAP; Transversus abdominis plane block, $*=$ compared to the control group. $\dagger=$ comparing the TAP group to the epidural group, TAP; Transversus abdominis plane block, $\mathrm{P}<0.05=$ statically significant.

Table (8): Average consumption of analgesia in the first 12 hours.

\begin{tabular}{|c|c|c|c|c|c|}
\hline & $\begin{array}{c}\text { Epidural } \\
(\mathbf{N}=\mathbf{3 0})\end{array}$ & $\begin{array}{c}\text { TAP } \\
(\mathbf{N}=\mathbf{3 0})\end{array}$ & $\begin{array}{c}\text { Control } \\
(\mathbf{N = 3 0})\end{array}$ & ANOVA & P- Value \\
\hline $\begin{array}{c}\text { Ketorolac } \\
(\mathrm{mg})\end{array}$ & $45.45 \pm 23.23 *$ & $50.50 \pm 18.18 *$ & $90.90 \pm 25.25$ & 5.423 & $<0.001 \mathrm{HS}$ \\
\hline $\begin{array}{c}\text { Pethidine } \\
(\mathrm{mg})\end{array}$ & $212.10 \pm 113.12 *$ & $194.93 \pm 94.94 *$ & $383.80 \pm 119.18$ & 7.230 & $<0.001 \mathrm{HS}$ \\
\hline
\end{tabular}

HS: Highly Significant

\section{Postoperative complications}

There was no statistical significant difference between group $\mathrm{E}$ and $\mathrm{T}$ in postoperative complications (Nausea, vomiting, requirement for antiemetic) in the first 12 hours postoperatively, where it didn't quietly occur (Table 9).

Table (9): Complications.

\begin{tabular}{|l|c|c|c|c|c|}
\hline & $\begin{array}{c}\text { Epidural } \\
(\mathrm{N}=30)\end{array}$ & $\begin{array}{c}\text { TAP } \\
(\mathrm{N}=30)\end{array}$ & $\begin{array}{c}\text { Control } \\
(\mathrm{N}=30)\end{array}$ & $\begin{array}{c}\text { Chi- } \\
\text { square }\end{array}$ & P- Value \\
\hline Nausea & $0(0 \%)^{*}$ & $0(0 \%)^{*}$ & $5(16.7 \%)$ & 10.588 & $0.005 \mathrm{~S}$ \\
\hline Vomiting & $0(0 \%)^{*}$ & $0(0 \%)^{*}$ & $3(10 \%)$ & 6.207 & $0.045 \mathrm{~S}$ \\
\hline $\begin{array}{l}\text { Frequency of doses of } \\
\text { Metoclopramide }\end{array}$ & $0(0 \%)^{*}$ & $0(0 \%)^{*}$ & $3(10 \%)$ & 6.207 & $0.045 \mathrm{~S}$ \\
\hline
\end{tabular}

S: Significant;

\section{Hospital length of stay}

There were no statistically significant difference in the length of hospital stay among the three groups (Table 10).
Table (10): Hospital length of stay.

\begin{tabular}{|c|c|c|c|c|c|}
\hline & $\begin{array}{c}\text { Epidural } \\
(\mathbf{N}=30)\end{array}$ & $\begin{array}{c}\text { TAP } \\
(\mathbf{N}=30)\end{array}$ & $\begin{array}{c}\text { Control } \\
(\mathbf{N}=30)\end{array}$ & $\begin{array}{c}\text { Kruskal } \\
\text { Wallis }\end{array}$ & $\begin{array}{c}\text { P- } \\
\text { Value }\end{array}$ \\
\hline $\begin{array}{c}\text { Days of } \\
\text { hospital stay }\end{array}$ & $2(2,4)$ & $2(2,4)$ & $3(2,4)$ & 0.342 & 0.076 \\
\hline
\end{tabular}

Data are represented as median (range); Lumber epidural analgesia, TAP; Transversus abdominis plane block, $\mathrm{P}>0.05=$ statistically not significant, $\mathrm{P}<0.05=$ statistically significant and $\mathrm{P}<0.001=$ high significant.

\section{DISCUSSION}

The MAP was slightly higher ingroup $\mathrm{C}$ than both groups $\mathrm{E}$ and $\mathrm{T}$ at $0,40,60$ minutes and at $2,4,6,12$ hours postoperatively with no statistical significance, but there a was highly significant increase in MAP ingroup C compared to both groups $\mathrm{E}$ and $\mathrm{T}$ at 10, 20 minutes.

The HR was slightly higher ingroup $\mathrm{C}$ than both groups $\mathrm{E}$ and $\mathrm{T}$ at $0,40,60$ minutes and at 2 ,4, 6, 12 hours postoperatively with no statistical significance, but there wasa highly significant increase in HR ingroup $C$ than both groups $E$ and $T$ at 10,20 minutes.

At the end of the surgery and before emergence from general anesthesia, both lumber epidural analgesia and TAP block were started. The effect of both analgesic modalities was realized especially after the first 10 and 20 minutes time periods. The lowest mean arterial blood pressure readings were observed within the group $\mathrm{E}$, in comparison with the other two groups; this could be due to sympathetic block of the lower half of the body yet no hypotension with reflex tachycardia was realized as patients were being well loaded.

Neither hypotension nor hypertension occurred within the TAP group. That's because the block itself does not interfere with the sympathetic innervations of the lower half of the body. More interesting, incidence of hypotension didn't occur among the three groups because the total requirement of opioids (i.e. Pethidine) used in each group was not that enough to cause hypotension.

Regarding heart rate remarked with the participants in the current study, none of the patients within the three groups showed an increase in the rate greater than 95 beats/minute or decrease lower than 70 beats/minute during the 12 hours postoperatively. 
This was proved as the mean value of heart rate among the three groups showed no statistical difference during the whole periods of assessment except at the first 10 and 20 minutes, after starting the epidural analgesia and application of the TAP block.

Higher readings of mean value of heart rate were recorded within the group $\mathrm{C}$ at these three specific time periods as reported in (Table 2), both lumber epidural and TAP groups showed no difference in their heart rates' records. This was mostly due to the analgesic effect of both lumber epidural and TAP blocks as being realized within the VAS records as mentioned in (Tables 4 and 5) at the corresponding times. Moreover, tachycardia due to hypotension in case of the epidural analgesia was prevented by well loading of the patients prior starting the epidural block in addition to low concentration local anesthetic.

On the other hand, Block et al. ${ }^{(\boldsymbol{6})}$ reported in a meta-analysis study an incidence of hypotension with a local anesthetic-based epidural analgesia regimen.

In our study the effect of the TAP block in preventing the variability in the hemodynamic status postoperatively, was the result of reduction in the incidence and severity of postoperative pain (VAS at rest and dynamic state). This is supported by what John et al. ${ }^{(8)}$, had realized when using this modality to prove its effectiveness in patients undergoing total abdominal hysterectomy. More interesting, TAP block was being chosen as adjunct to general anesthesia by French et al., (9), when being faced by a pregnant patient with intracranial tension for whom a decision for termination of pregnancy by an elective cesarean was performed. The main goals for that were planned to maintain the cardiovascular stability, control intracranial pressure during general anesthesia, together with providing adequate postoperative pain relief with minimal opioid requirements, thus reducing their systemic side effects (e.g., respiratory depression and neurological deterioration).

Another case report about the effectiveness of using bilateral TAP block for analgesia following cesarean delivery was performed by Scharine ${ }^{(10)}$, that provided effective analgesia thus reducing the postoperative pain scores (VAS at rest and at dynamic state), which maintained the cardiovascular stability.

Moreover, the cardiovascular protective effect of TAP block was reported by O'Donnell $\boldsymbol{e t}$ al., (11), when used as an analgesic technique modality in open retro-pubic prostatectomy. No side effects were being noticed; first due to effective analgesia thus reducing the postoperative pain scores (VAS at rest and at dynamic state), which maintained the cardiovascular stability, second, only few patients among the TAP group asked for postoperative rescue analgesia.

There was no statistical significant difference inboth VAS and VAS with knee flexion among the three groups at $0,40,60$ minutes and at 2,4, 6 hours postoperatively, but there was high significant decrease in VASin both groups lumber epidural and TAP thangroup $\mathrm{C}$ at 10,20 minutes $(\mathrm{P}<0.001)$.

There wasa high significant difference in the time to first request of analgesia among the three groups, TAP group showed the highest time, whilegroup $\mathrm{C}$ showed the lowest time.

There wasa high significant decrease in frequency of analgesia in the first 12 hours in both groups lumber epidural and TAP than group $C$.

There wasa high significant decrease in the average total consumption of analgesia in the first 12 hours in both groups lumber epidural and TAP than group $\mathrm{C}$.

The higher readings of VAS were realized among the control group at 10, 20 minutes, mostly due to the rapid onset of action of the bupivacaine used by the other two groups, as occurred within the first 10 minutes of time reaching the peak effect within the next 10 minutes as seen in (Tables 4 and 5). This also was proved as the first time of asking for rescue analgesia was delayed in both the epidural and TAP group while it was too early within the control one as being illustrated in (Table 6).

The idea that the TAP block may reduce opioid requirements after a single shot injection was proved by McDonnell et al., (12) to last for 12 hours. The reasons for the prolonged duration of analgesic effect after TAP blockade are not entirely elucidated. However, this may be related to the fact that the TAP is relatively poorly vascularized; and therefor, drug clearance may be slowed.

In a study done by Niraj et al., ${ }^{(13)}$ found that pain after surgery for acute appendicitis, which arise mainly from the surgical wound on the anterior abdominal wall and inflammation of the infected appendix was powerfully controlled among patients who received the TAP block. There were significantly reduction in the pain scores with a 
mean VAS scores at rest to be 2 with a range of 1.53.2 at 30 minutes postoperatively and 2 with a range of 1-2.8 at 24 hours postoperatively with $P<0.001$ in comparison to standard use of systemic morphine as a rescue analgesia. The pain control effect of TAP block in this study was supported by the reduction in the total consumption of morphine among TAP block group.

Since local anesthetic infiltration in the surgical wound can be an alternative to TAP block in patients undergoing open appendectomy; however, duration of action is short (2-6 hours) ${ }^{(\mathbf{1 4})}$.

In the current study comparing the pain scores of TAP block and epidural analgesia, there was no statistical difference although the period of assessment especially in the first 12 hours postoperatively in comparison to GA group, which showed higher values of mean VAS at rest and dynamic state, that's because of the direct action of bupivacaine on the abdominal wall supplying nerves, together with interfering with the pain cycle.

Recently, in patients undergoing laparoscopic cholecystectomy, subcostal TAP block was reported to produce better analgesia than classic TAP block or intravenous opioid analgesia during the postoperative 24 hr period ${ }^{(15)}$.

Wu et al. $^{(\mathbf{1 6})}$ reported that single-injection subcostal TAP block provides effective postoperative analgesia at rest and while moving compared to intravenous opioid analgesia during upper abdominal surgery. In the same study, continuous epidural analgesia was shown to provide more effective analgesia than single-injection subcostal TAP block, which had increased morphine consumption for 6 to 24 hours and pain scores in the post anesthesia care unit (PACU) and beyond 6 hours postoperatively, that was attributed to reasons like, that TAP block only provides somatic pain relief as opposed to epidural anesthesia which provides both somatic and visceral analgesia; also, the efficacy of single-injection subcostal TAP block will wane over time, while that of thoracic epidural catheters can be sustained ${ }^{(16)}$.

In contrast, Chen et al., (17) observed no difference in analgesic efficacy between TAP block and intravenous morphine during the postoperative period.

Comparing the VAS analysis of TAP block in the current study with that of John et al. ${ }^{(8)}$, when used this modality to prove its effectiveness, it was found that the VAS analysis turned to be almost similar to the results of the present study, as a collective of VAS of 3 with a range of (1-4) within the first 2 hours period postoperatively.

Moreover, using of the TAP block technique as an analgesic technique modality in open retropubic prostatectomy by O'Donnell $\boldsymbol{e t} \boldsymbol{a l}$. (9), showed a mean of VAS of 1.5 with a range of 0 to 7 seen at 6 hours postoperatively. In comparing the result of this study to that of the current study as presented in tables 4 and 5, it was found that max range of VAS in the TAP group ranged from 1 to 3.5 at 6 hours, postoperatively. This shows that the volume used in the current study, $30 \mathrm{ml}$. of $0.125 \%$ bupivacaine per injection, was more effective than that used by O'Donnell et al. (10), which was $20 \mathrm{ml} .0 .375 \%$ bupivacaine.

In agreement to the current study, a metaanalysis search done by Marret $\boldsymbol{e t} \boldsymbol{a l}^{(\mathbf{1 8 )}}$, for the period time 1966 to 2004, comparing the use of parenteral opioids to the epidural analgesia proved that epidural analgesia provided significantly better postoperative analgesia compared to intravenous opioid analgesia $(P<0.001)$, at all intervals up to 3 days after surgery either for pain at rest or with activity.

More interestingly, Marret et al. ${ }^{(18)}$ searched the efficacy of different epidural regimens ('opioid alone' [hydrophilic versus lipophilic] versus 'local anesthetic + opioid' versus 'local anesthetic alone') all epidural regimens provided significantly superior analgesia versus intravenous analgesia for overall pain (pain at rest or with activity).

Other systemic review by Dolin et al., (19), showed the effectiveness of acute postoperative pain management using a numerical rating scale to assess pain and pain relief, found that when compared with intravenous analgesia, the use of postoperative epidural analgesia resulted in a significantly lower incidence of pain with moderate to severe pain $(20.9 \%$ versus $35.8 \%$ intravenous analgesia and $67.2 \%$ intramuscular) and severe pain $(7.8 \%$ versus $10.4 \%$ intravenous analgesia and $29.1 \%$ intramuscular) ${ }^{(6)}$.

In agreement with the present findings, Shir $\boldsymbol{e t}$ al., ${ }^{(20)}$, showed that epidural analgesia resulted in less postoperative analgesic requirements for similar efficacy compared with general anesthesia alone and that the blockade of afferent noxious input was important in the management of postoperative pain ${ }^{(21)}$.

On the other hand, well-designed prospective double-blind studies have found only limited ${ }^{(22)}$ or no benefits of epidural analgesia over intravenous 
analgesia techniques on the outcome after major abdominal surgeries ${ }^{(21)}$.

On the contrary, Gupta et al., ${ }^{(21)}$ found a significant reduction in pain intensity by $40-50 \%$ compared with intravenous analgesia, as lower pain scores were found in static pain (incision site) as well as dynamic pain (on coughing) together with improvement in the expiratory function, and this was clearly evident during the 24 hours postoperatively.

To sum up, in the current study comparing the pain scores of TAP block and lumber epidural analgesia, it was concluded that there were no statistically differences through the first 12 hours postoperatively with a postoperative mean VAS of 2 (1-3.5) at rest and 2 (1.5-3.5) with knee flexion for both groups. This shows that both techniques provide good analgesia when compared to GA group which showed a mean VAS of 4.5 (3.5-6.5) at rest and 4.5 (4-6.5) with knee flexion at the same time, that's because of the direct action of the local anesthetic used on the supplying nerves, thus interfering with the pain cycle.

There was no statistical significant difference in RR among the three groups at 0,40 , 60 minutes and at 2, 4, 6, 12,hours, but there was high significant increase in RR in GA group than both groups $\mathrm{E}$ and $\mathrm{T}$ at 10, 20 minutes.

There were no records of respiratory rate below 10 breaths per minute among the three groups during the first 12 hours postoperatively. The rate of administration of the rescue analgesia was more frequent among patients of the GA group rather than the other two groups as seen in (Table 10), yet no respiratory distress was realized among the three groups.

The higher readings of $\mathrm{RR}$ were realized among the GA group at 10 minutes and 20 minutes time periods, mostly due to the difference in pain score between the GA group and the other two groups, supported by the readings of VAS score, which showed significant increase in pain score in the GA group in comparison to the other two groups at these two time periods.

There was statistical significant difference in postoperative complications (nausea, vomiting, requirement for antiemetic and pruritus) in the first 12 hours, where it didn't quietly occur in groups $\mathrm{T}$ or $\mathrm{E}$.

Postoperative nausea and vomiting (PONV) are being the common irritating complains to any patient especially during the first 12 hours following surgery, for fearing of wound dehiscence. Since opioids given via intravenous method proved to have several disadvantages, including PONV and a delay in the recovery of body functions such as bowel movement and mobilization, several studies have focused on the use of regional analgesia to overcome this complain postoperatively ${ }^{(23)}$.

Data represented in this study showed that postoperative complications as, (nausea and vomiting), which resulted due to systemic use of opioids were mostly among the GA group rather than the other two groups with $(P<0.05)$. The reason for this could be that the requirement of Pethidine among the control group was higher than that among the other two groups as seen in (Tables 8 and 9).

In agreement with our conclusions, Sharma et al. ${ }^{(24)}$ reported that the incidence of PONV was reduced by more than half in the TAP block group.

Regarding PONV in the current study, no patient among either the TAP group or the epidural one has experienced pruritus, that's may be because the total requirements of Pethidine among these two groups were not enough to cause PONV, while it was found to be mostly among the GA group who depend mainly on the systemically given opioids for rescue analgesia, in comparison to the other two groups.

Regional analgesia, specifically epidural analgesia, has been a popular alternative, thus proved to have several advantages over systemically given opioids. The cumulative incidence of nausea and vomiting in patients receiving continuous infusions of opioids was high as $45 \%$ to $80 \%$ in their study ${ }^{(25)}$.

On the contrary, Gupta et al. ${ }^{(21)}$,reported the advantage of epidural analgesia over intravenous patient controlled analgesia (PCA) as regarding reduction in the incidence of $\mathrm{PONV}$ as well as pruritus.

General speaking comparing epidural

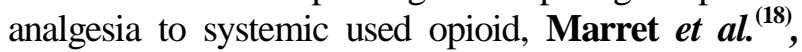
found that the analgesic effect of the epidural analgesia was statistically superior to systemically given opioids, together with lower incidence of PONV, yet the incidence of pruritus was common. This might be the effect of the used opioid as an adjunct to local anesthetics. That's to say that PONV and pruritus are mostly seen as common postoperative side effects of opioids either as being systemically applied or used within the epidural analgesia depending on the dose given in susceptible patients.

The results of the present study regarding the incidence of postoperative complications following TAP 
technique were being supported by what had been published

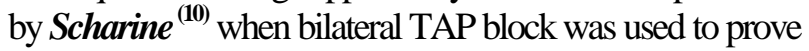
its analgesic effect following cesarean delivery.

Somewhat surprisingly, given the reduction in the postoperative opioid requirements, the TAP block did not reduce the incidence or the severity of PONV as reported by McDonnell et al., ${ }^{(12)}$, when bilateral TAP block was used following abdominal hysterectomy.

This might have been because the amount of opioid used among the TAP group was sufficient to produce PONV. Regarding incidence of postoperative pruritus within the same study, it was mostly among the control group $(P<0.001)$ who depend mainly on the systemically given opioids for rescue analgesia, in comparison to the TAP one.

On the other hand, there was no significant difference in the incidence or severity of PONV among the control group and the TAP group when Niraj et al. ${ }^{(13)}$ used the TAP block following appendectomy, yet the standard group required significantly more rescue anti emetics than the TAP group.

More interestingly, no patient required rescue opiate analgesia in a study done by O'Donnell et al. ${ }^{(9)}$, who used TAP block in open retro-pubic prostatectomy thus no postoperative complications were reported, neither suffered an adverse events as a result of the TAP block.

As regard local anesthetic (bupivacaine) consumption, there was no statistically significant difference in bupivacaine consumption between groups $\mathrm{T}$ and $\mathrm{E}$. But there was a significant difference in both groups $\mathrm{T}$ and $\mathrm{E}$ compared to GA group as no local anesthetic given in GA group.

Generally speaking, when compared with epidural analgesia, TAP analgesia does not cause hemodynamic imbalance, preserves motor function of the lower limbs and can be used in patients requiring anticoagulation medication. Transversus abdominis plane analgesia does not require intensive nursing care and does not cause urinary retention ${ }^{(13)}$. However, there are well-known side effects and potentially catastrophic risks to the epidural technique as well as a reported failure rate ranging from $17 \%$ to $37 \%{ }^{(\mathbf{1 9})}$.

\section{CONCLUSION}

The abdominal wall became to be a significant source of pain after abdominal surgeries such as appendectomy, caesarian section and hernioraphy, these patients require postoperative pain control regimen that provides high quality analgesia with minimal side effects. Use of the TAP block proved to be a simple and safe procedure in providing effective reliable analgesia, together with reduction of postoperative pain scores, both at rest and knee flexion, and postoperative opioid requirements thus avoided any of the systemic side effects of opioid such as PONA as seen among the control group.

\section{REFERENCES}

1. Manion $S$ and Brennan $T$ (2011): Epidural Analgesia and Acute Pain Management, the American Society of Anesthesiologists, Inc. Lippincott Williams \& Wilkins. Anesthesiology, 115:181-8.

2. Atkinson R, Rushman G and Lee J (1987): A synopsis of anesthesia, $10^{\text {th }}$ ed. Bristol: Wright, 637-640.

3. Rafi A (2001): Abdominal field block: a new approach via the lumbar triangle. Anesthesia, 56: 1024-26.

4. Hebbard P, Fujiwara Y, Shibata $Y$ and Royse $C$ (2007): Ultrasound-guided transversus abdominis plane (TAP) block. Anesthesia and Intensive Care, 35: 616-7.

5. Young $M$, Gorlin $A$, Modest $V$ and QuraishiS (2012): Clinical Implications of the Transversus Abdominis Plane Block in Adults, Anesthesiology Research and Practice, doi:10.1155/2012/731645.

6. Block BM, Liu SS and Rowlingson AJ (2009): Efficacy of postoperative epidural analgesia: a meta-analysis. JAMA., 290:2455-63.

7. Carli F, Mayo $N$ andKlubien $K$ (2002): Epidural analgesia enhances functional exercise capacity and health-related quality of life after colonic surgery: results of a randomized trial. Anesthesiology,97: 540-9.

8. John C, McDonnell JG, Ochana A, Bhinder R and Laffey JG (2008): The transversus abdominis plane block provides effective postoperative analgesia in patients undergoing total abdominal hysterectomy. AnesthAnalg., 107:2056-60.

9. French JL, Mccullough J, Bachra $P$ and Bedforth NM (2009): Transversus abdominis plane block for analgesia after Caesarean section in a patient with an intracranial lesion, Int J ObstetAnesth.,18: 52-54.

10. Scharine JD (2009): Bilateral Tranversus Abdominis Plane Nerve Blocks for Analgesia Following Cesarean Delivery: Report of two cases, AANA Journal, 77: 98-102. 
11. O'Donnell BD, McDonnell JG andMcShane AJ (2006): The transversus abdominis plane (TAP) block in open retropubic prostatectomy, RegAnesth Pain Med., 31: 91.

12. McDonnell JG, Curley G, Carney J, Benton A, Costello J, Maharaj CH andLaffey JG (2008): The analgesic efficacy of transversus abdominis plane block after cesarean delivery: a randomized controlled trial, AnesthAnalg.,106, 1: 186-91.

13. Niraj G, Kelkar A, Hart E, Horst C, Malik $D$, Yeow C, Singh $B$ and ChaudhriS (2014):Comparison of analgesic efficacy of four-quadrant transversus abdominis plane (TAP) block and continuous posterior TAP analgesia with epidural analgesia in patients undergoing laparoscopic colorectal surgery: an open-label,randomised, non-inferiority trial, Anaesthesia, 69: 348-355.

14. Ballantyne JC, Carr DB, Suarez T, Lau J, Chalmers TC, Angelillo IF andMosteller F (1998): The comparative effects of postoperative analgesic therapies on pulmonary outcome: cumulative meta-analyses of randomized, controlled trials. Anesthesia \& analgesia, 86(3):598-612.

15. Shin HJ, Oh AY, Baik JS, Kim JH, Han SH, Hwang JW (2014): Ultrasound-guided oblique subcostal transversus abdominis plane block for analgesia after laparoscopic cholecystectomy: a randomized, controlled, observer-blinded study. Minerva Anestesiol.,80(2):185-93.

16. Wu C, Cohen S, Richman J(2005): Efficacy of Postoperative Patient-controlled and Continuous Infusion Epidural Analgesia versus Intravenous Patient-controlled analgesia with opioids, Anesthesiology, 103: 1079-88.

17. Chen CK, Tan PC, Phui VE, Teo SC (2013): A comparison of analgesic efficacy between oblique subcostal transversus abdominis plane block and intravenous morphine for laparascopic cholecystectomy. A prospective randomized controlled trial. Korean journal of anesthesiology, 64(6):511-6.

18. Marret E, Remy $C$ and Bonnet F (2007): Meta-analysis of epidural analgesia versus parenteral opioid analgesia after colorectal surgery. British Journal of Surgery: Incorporating European Journal of Surgery and Swiss Surgery, 94(6):665-73.
19. Dolin SJ, Cashman JN and Bland JM (2002): Effectiveness of acute postoperative pain management, Br J Anaeth., 89: 409-23.

20. Shir Y, Raja SN and Frank SM (1994): The effect of epidural versus general anesthesia on postoperative pain and analgesic requirements in patients undergoing radical prostatectomy, Anesthesiology, 80(1):49-56.

21. Gupta S, Sivapurapu V, Vasudevan A and Badhe A (2013): Comparison of analgesic efficacy of transversus abdominis plane block with direct infiltration of local anesthetic into surgical incision in lower abdominal gynecological surgeries. J Anaesthesiol Clin Pharmacol., 29(1):71-5.

22. Rigg JR, Jamrozik K, Myles PS andSilbert BS (2002): A randomized trial of epidural anesthesia and analgesia and outcome of major surgery, Lancet,9314: 1276-82.

23. Kehlet $H$ and Dahl JB (2003): Anesthesia, surgery, and challenges in postoperative recovery, Lancet, 362

24. harma P, Chand T, Saxena A, Bansal R, Mittal A andShrivastava U (2013): Evaluation of postoperative analgesic efficacy of transversus abdominis plane block after abdominal surgery: A comparative study. J Nat ScBiol Med., 4:177-80.

25. Nakata $K$, Mammoto $T$ and Kita $T$ (2002): Continuous epidural, not intravenous, droperidol inhibits pruritus, nausea and vomiting during epidural morphine analgesia, J ClinAnesth.,2: 12125. 